\title{
IMPROVEMENT OF THE METHODOLOGY OF RESEARCHING PROBLEMS OF EDUCATION
}

\author{
Kuznetsova A.Ya. \\ Novosibirsk State Pedagogical University, Novosibirsk,e-mail:phileducation@yandex.ru \\ The article in the discourse of historical development presents the consistent development of scientific ap- \\ proaches in education based on their methodological improvement. To solve the problem, two features of the devel- \\ opment of theoretical knowledge about education were taken as a basis: 1- the ever-increasing deepening of theoreti- \\ cal research and 2- the use of all possible innovations in the field of methodology by the humanities, including those \\ obtained as a result of integration processes in science. It is shown that modern research methodology is necessary \\ for the design of future education. The inclusion of the tasks of comprehending the methodology in the content of \\ education is noted. An analysis of the modern content of the updated methodological categories is given: goals, \\ objectives, methods, etc. The growth in the share and influence of educational sciences is indicated. It is proved that \\ the development of the theory of education of the 20th century is reflexively consistent with the methodology of \\ classical science. The methodological features of the humanistic approach in the second half of the XX century are \\ presented. It is shown that the reflection included in the model of the "trajectory of individual development" brings \\ the content of modern education to a higher innovative methodological level.
}

Keywords: methodology, theoretical knowledge, purpose of research, subject of research, reflection, post-non-classical science

Science has an ever-increasing influence on society as a whole and on its individual components. Over time, the field of scientific research grows, and the object of scientific research also changes. In addition, the subject of research in the same branch of science changes over time, which imposes new requirements on the methodology used in modern research. At the beginning of the 20th century, the theoretical understanding of the problems of education led to the need for scientific confirmation of knowledge about education. The scientific and theoretical equipment of education is consistent with the general development of the humanities, at present - with the general postnon-classical methodology of cognition. The rethinking and organization of the scientific method is constantly happening.

The change in methodologies in science is due to the reflexivity of thinking, its development and strengthening during periods of changing scientific paradigms. The growth of the mass of scientific knowledge in education and, at the same time, integration processes with other sciences at the end of the twentieth century demanded a transformation, improvement of the apparatus of scientific methodology. The movement of the theory of education towards the development of a scientific methodological style follows the deepening of research on the content of education. As a result, the methodological improvement of the theory of education is motivated by both transformations in the life of society and the internal tasks of the development of science. Along with new scientific knowledge, new methodological principles come to the content of education. The analysis of knowledge, skills and abilities in the first half of the twentieth century made it possible to comprehend and structure the competence-based approach in education. The subsequent transition to understanding the individual approach in the second half of the twentieth century brought the theory of education to the main personality-oriented direction with corresponding changes in the methodological apparatus.

Modern tasks of improving professional competence require understanding the problems of preparing a new generation of citizens for a digital society while maintaining the personality-oriented features of the existing education system. The content of education is expanding taking into account the new provisions of the psychology of higher mental processes, the psychology of reflexive processes, models of intellectual activity, theoretical elaborations of individual trajectories of development. At present, when discussing the problems of development in education, it becomes relevant to master the system of new psychological and pedagogical knowledge in the field of intellectual reflection. When developing and understanding individual trajectories of development, it will be necessary to use a methodology based on the reflexivity of the researcher and the research methods he uses. The general strengthening of the methodological reflexivity of science lies in the fact that the research methods themselves, the genetics of cognition, the logic of thinking. Analysis of changes in the methodology of education makes it possible to trace the process of integration of science and education in a separate field of knowledge. At present, the general processes of integration of science and education are moving to the level of integration of methodologies, the leading among which in the twentieth century 
was the methodology of natural sciences. The development of educational projects is necessary for society to update social reality. The accumulated experience in the application of the scientific method has made it possible to obtain significant achievements in the study of natural and social phenomena, which emphasizes the need to increase attention to the use of the scientific method in solving educational problems.

The development of modern methodology is combined with the involvement of world scientific experience in the field of education. The personality-oriented humanistic direction developed in pedagogy, built on the recognition of personality development as the goal of education, is widely accepted in world science. The humanistic approach has become established in pedagogy on the views of the need to educate an integral personality, on the creation of conditions for the manifestation of a person's natural potential. The next step was the recognition of subject-subject relations. The combination of the subject and the goal of research in the educational processes led to changes in the subject and goals of research. The dynamic change in leading approaches and the development of new ideas make adjustments to the theory of education and require further improvement of the methodology of psychological and pedagogical research.

Literature review. Modern research continues to solve the problem of clarifying the principles of methodology and the content of methodological categories of scientific research in education. This is necessary for the development and construction of prospects for further scientific work [1]. Researcher Berehova G. [2] shows that the methodological vector of education is aimed at shaping the image of a person of the future, his mentality, worldview [3]. The authors argue that such a strategy makes it possible to take into account both the global transformations of modern society and the attitude towards its moral and value foundations. Thus, modern studies of methodology are aimed at obtaining the knowledge necessary for the design of the future general education and the development of a specific personality in it. The study of the competencies necessary for society suggests that the scientific and methodological tool of various forms of education: formal and informal, can be aimed at enhancing the effectiveness of the vocational training process, at improving the competence direction in the preparation of future teachers, in this case - social. According to the research plan, work is being carried out on the content of the methodological tools, on the scientific substantiation of its systematization.

The modern content of the updated categories is being worked out: goals, objectives, methods and other methodological categories that provide the content of increasing professional competence. The concept of "learning space" is being developed as an "updated" methodological category. The project of the learning space is focused on the formation of competencies, their assimilation through experience. Methodological tools in the educational space are presented in each of its constituent blocks: communicative, empirical, theoretical [4]. The study of the design of scientific activities in the higher education system also begins with an understanding of the methodological foundations. Kozlovskiy Yu relates the methodological foundations of scientific activity to scientific philosophy. It is shown that researchers move to the level of philosophy in those cases when they encounter specific contradictions that arise in the analysis of research activities. The author notes that when designing scientific activity, there are manifestations of the law of the unity of opposites, the law of negation and the transition from formal quantitative indicators to qualitative descriptions of results, etc. [5]. The study of the design of scientific activities in the higher education system also begins with an understanding of the methodological foundations. Kozlovskiy $\mathrm{Yu}$ relates the methodological foundations of scientific activity to scientific philosophy. It is shown that researchers move to the level of philosophy in those cases when they encounter specific contradictions that arise in the analysis of research activities. The author notes that when designing scientific activity, there are manifestations of the law of the unity of opposites, the law of negation and the transition from formal quantitative indicators to qualitative descriptions of results, etc. [5].

Also, the methodological problem of unity and development of harmony is referred to the philosophical discourse. In the study, it is presented as a variant of the anthropocosmic view of the world. A number of other anthropocosmic problems are outlined: the integrity of man and space; the unity of the universe and man; approval of the harmony of the new planetarycosmic worldview. All the questions raised are united by the problem of a holistic vision of man as a noospheric vector of the generation of mankind [6].

An analysis of the relationship between philosophy, methodology of science and science in general is offered by Makuhin P.G. [7] in the 
article "The modern meaning of the antinomy of philosophy. Scientific status as metaphysics in Immanuel Kant's "critical philosophy" [7]. The problem of the structure of modern knowledge, its methodological capabilities and the scientific nature of the method of metaphysics are discussed. In the article Kolomiychenko L.V. modern educational space is defined as multi-paradigm. The problems of preschool education are comprehended at the intersection of two paradigms: cultural and humanistic [8]. In the practice of modern education, a methodological basis for research in the cultural and humanistic paradigms of preschool education is being developed. The program-target, technological and monitoring components of the educational process of preschool children are identified as significant.

According to the author of the article "Dialogue as a method of modern education" [9], the methodological significance of dialogue in education consists in the choice of the subject of the study of the student himself, who as a result becomes a subject. As a result, dialogical, existential, hermeneutic and synergetic approaches are proposed. The method of dialogue transfers the educational process to the level of subject-subject relations. The study of a specific method allows in the process of developing a research procedure carried out on the basis of a systematic approach to improve the general methodology of education [9].

Izotov M.Z., Turyszhanova R.K. also methodologically update the subject of research, proceeding from the fact that scientific knowledge is a social and human phenomenon. The development of science is presented as a necessary component of social development. With this approach, the picture of the world, which includes a person as a social being, is reflected as a picture of the second nature. The peculiarities of such a second nature is that the subject of knowledge becomes at the same time its object. The second nature, in contrast to the first, is a humanized world that includes a social person as one of the forms of nature. The methodological decision regarding the subject of research required a more careful consideration of the value of scientific research. Scientific knowledge, which becomes the value of society, inevitably leads to the need to improve scientific methodology [10]. Scientific research of the worldview components of individual consciousness and public consciousness also required the awareness of special methodological categories: the goal and subject of research. The study of the content of the subject of research reveals the unity of nature, society, (intrascientific) cognitive and natural capabilities of the individual.

The problem and purpose of the study. Education at the beginning of the 20th century, starting to master the competence-based scientific approach, used the classical methodology. The expansion and strengthening of the influence of science on social processes, the mass character and intellectualization of education, the strengthening of the value of education for the society of the XXI century impose methodological requirements on the science of education itself. The purpose of this study is to show how in the process of cultural and historical strengthening of the influence of science on the life of society, changes are made in science itself, its methodology is transformed. Show how, in the process of establishing the science of education, the influence of psychology, sociology and philosophy is increasing in it. The purpose of this work is to show that historically, during the 20th century, the field of scientific research of educational problems is not only strengthened, but also expanded, a higher methodological level of science is formed and developed, ensuring its rigor, consistency and purposefulness. Such a scientific narrative of education can ensure the productivity of its social function in an information science and technology society.

Research results and discussion. It is known that the classical methodology, on the platform of which the science of education began to form, with the deepening of research, came into conflict with the subject of research - multifactorial processes of teaching, upbringing, development, and other processes of human education. By this time, natural science had already approached the solution of a similar problem - the problem of "the role of the device in the experiment" [11]. At the same time, a consistent complete description of natural phenomena is achieved at the cost of refusing to unambiguously separate them from the observer, and since then he is a device-researcher himself, the principle of complementarity, which includes the idea that "... in every message containing a reference to ourselves, we, so to speak, introduce a new subject, which is not the subject of our message "[11, pp.525]. Pauli, further generalizations, the inclusion of a human researcher in the general scientific picture of nature, make it necessary to base research on "the integrity of a living organism and the unity of the individual" [12, pp. 355].

Pedagogical science is developing simultaneously with natural science. At the beginning of the 20th century, they do not intersect 
methodologically. A special place in the framework of the humanistic scientific and pedagogical community is occupied by the activities of P.P. Blonsky and M.M. Rubinstein. Systematic analysis of their publications in 1911-1917. shows that scientists have developed an integral concept, which is close, in fact, to the model of the school of "personal self-realization", insisting on the scientific nature of pedagogy. The future humanistic folk school of P.P. Blonsky should be a school of humanity. Its task is to create a person sensitive to human life, who would like and know how to see the life of his brothers. She must tell the person about the person. In the writings of the early 20th century, P.P. Blonsky wrote about the need for self-reflection, self-determination and rational organization of self-education. P. P. Blonsky and M. M. Rubinshtein formulated a conceptual model of the "human-centric" school. Methodologically, it contained the goal, content and forms of education, comprehended in the model of the unity of socio-historical and personal-educational spaces.

The methodological approach in pedagogy, continuing its improvement during the XX century, acquires generating, critical, predictive and integrating functions [10]. The generating function of methodology in education theory involves setting new goals, solving new problems and using new methods. The critical function of the methodology is based on the strengthening of its reflexivity, consists in the fact that the categorical apparatus and the content of the theory of education are constantly rethought. The predictive function of the methodology brings it to the level of metatheory, opens up opportunities for a strategic approach in education, it is based on continuous clarification of the goal, subject and research methods. The integrating function of the methodology is to equip the researcher with the knowledge synthesis methodology, to develop in him the intellectual ability to integrate. The integrating function of philosophy lays the foundation for the ideological function, the formation of which is consistent with the cultural and historical background of the era.

The reflexivity of the methodological approach in education in education helps to reveal the process of the formation of the personality, the spiritual development of a person, realized by their own intellect. Strengthening the reflexivity of the methodological approach in education is necessary, since reflection breaks off not only a higher level of comprehension of the theory of education, but also the path to self-knowledge [13]. Possession of the method provides a feedback (reflexive) connection of cognition, starting with the method of individual self-knowledge and ending with the highest level of reflection - the general methodology of sciences. In pedagogy, the methodological approach allows you to find the optimal path of development, both theory and practice of education.

Conclusions. At the present stage, the development of the science of education is largely due to the improvement of its methodology, the strengthening of the reflexivity of modern education and science, including the methodology of science. Reflexive deepening of individual and collective scientific knowledge on the basis of improving the methodology of cognition presupposes a renewal of the picture of the world. The formation of a more holistic picture of the world presupposes the inclusion of the human researcher into it. Proceeding from the assumption that there is no sharp dividing line between the physical and the mental, we come to an understanding of the commonality of the epistemological foundations of humanitarian and natural science research, the methodologies of their cognition in the context of the development of modern integrated knowledge. In post-non-classical natural science, the joint consideration of thinking and experience has become part of methodology. It was this direction of philosophical reflection, as well as the amazing development of technology that ensured progress in natural science in the 20th century.

The formation of a personality-oriented approach in education is based on the idea that cognitive activity always includes the knowledge of the subject of research. To identify this component, self-knowledge reflection is necessary. Methodologically, in modern education research, the assertion of ideas about personal development and reliance on the ability of the individual intellect to reflect were most expressed in projects of the individual trajectory of development [14].

\section{References}

1. Taber K.S. Methodological issues in science education research: a perspective from the philosophy of science // International handbook of research in history, philosophy and science teaching. 2014. pp. 1839-1893.

2. Berehova G. Philosophy of education: main methodological vectors of moulding the person of the future in higher education // Future Human Image. 2017. T. 8. pp. 14-29.

3. Kuznetsova A. YA. Methodological unity of scientific perception and humanistic philosophy of education // European Journal of Natural History. 2007. N3. pp. 136-137.

4. Pavlyk N.P. Scientific and methodological instrument for inorgan education in professional preparation of fu- 
ture social pedagogies // Balkan Scientific Review. 2018. N 1. pp. 64-68.

5. Kozlovskiy Yu. Methodological bases of design the scientific activity of higher education institution in the context of philosophy laws // Problems of Engineering Pedagogic Education. 2012. N 34-35. pp. 30-36.

6. Berehova H. The philosophy of unity and development of harmony as a variant of the anthropocosmic world view // Philosophy and Cosmology. 2017. T. 18. pp. 104-111.

7. Makuhin P.G. Present value of antinomy of philosophy scientific status as metaphysics in immanuel kant's "critical philosophy" // Eastern European Scientific Journal. 2014. N 3. pp. 288-291.

8. Kolomiychenko L.V. Culturological paradigm of education as a humanistic base of pre-school aged children education // Life Science Journal. 2014. T. 11. N 12. pp. 348-351.
9. Kostadinovich D.D. Bondareva Ya.V. Dialogue as a method of modern education // Bulletin of the MSRU. Series: Philosophy. 2020. N 2. pp. 27-34.

10. Kuznetsova A.Ya. Functional foundations of modern philosophy of education // Modern high technologies. 2010. N 8. pp. 85-86.

11. Bor N. Physical science and the problem of life // Selected Scientific Works. T.2. M., 1971. pp. 518526.

12. Pauli V. Works on quantum theory // General principles of wave mechanics. M., 1975. pp. 352570.

13. Kuznetsova A.Ia. Reflexive mechanisms of modern educational activity // European Journal of Natural History. 2020. N 3. pp. 60-64.

14. Kuznetsova A.Ya. Fundamentalization and technology of development of the ideas of individual trajectory in education // Scientific Review. Pedagogical sciences. 2020. N. 5. pp. 31-35. 